\title{
RANDOM WALKS RELATIVE TO MULTIPLE TRANSITION MATRICES
}

\author{
ANTONIJA PRŠLJA
}

\begin{abstract}
Given the cost matrix corresponding to transitions between states, the mean of the cost along a random walk of a prescribed length needs to be computed in many applications. We introduce a generalization of the model for multiple transition and cost matrices and propose Monte Carlo techniques to solve it. Experiments on artificial data and a small example of simulated bike sharing system are conducted to evaluate the performance of the presented approaches in comparison with the ones based on computing powers of matrices.
\end{abstract}

Mathematics subject classification (2010): 60J22.

Keywords and phrases: Multiple transition matrices, cost matrix, Monte Carlo method, random walk, discrete Markov chain.

\section{REFERENCES}

[1] S. Asmussen And P. W. Glynn, Stochastic Simulation: Algorithms and Analysis, Springer, New York, (2007).

[2] K. Au, G. Byrnes, C. Bain, M. Fackrell, C. Brand, D. Campbell and P. Taylor, Predicting Overflow in an Emergency Department, IMA Journal of Management Mathematics, 20 (2009), 39-49.

[3] C. Bain, P. Taylor, G. Mcdonnell and A. Georgiou, Myths of ideal hospital occupancy, Medical Journal of Australia, 192 (2010), 42-43.

[4] S. Brooks and A. Gelman And G. L. Jones And X. Meng, Handbook of Markov Chain Monte Carlo, Chapman \& Hall, New York, (2011).

[5] L. Caggiani And M. Ottomanelli, A dynamic simulation based model for optimal fleet repositioning in bike-sharing systems, Procedia - Social and Behavioral Sciences, 87 (2013), 203-210.

[6] G. Casella And C. Robert, Monte Carlo Statistical Methods, Springer Verlag, New York, (2004).

[7] R. R. Coifman And M. Maggioni, Diffusion wavelets, Applied and Computational harmonic Analysis, 21 (2006), 53-94.

[8] E. Côme And L. Oukhrllou, Model-Based Count Series Clustering for Bike Sharing System Usage Mining: A Case Study with the Vélib' System of Paris, ACM Transactions on Intelligent Systems and Technology, 5 (3), (2014), 39:1-39:21.

[9] T. H. Cormen And C. E. Leiserson And R. L. Rivest and C. Stein (Eds), Introduction to Algorithms, The MIT Press

[10] P. L'ECuyer And C. Lecot And B. Tuffin, A Randomized quasi-Monte Carlo Simulation Method for Markov Chains, Operations Research 56 (2008), 958-975.

[11] P. Fearnhead and C. Sherlock, An exact Gibbs sampler for the Markov-modulated Poisson process, J. R. Statist. Soc., B 68 (2006), 767-784.

[12] W. R. GiLks (Eds), Markov chain Monte Carlo in practice, Chapman \& Hall, London, (1996).

[13] P. Glasserman (Eds), Monte Carlo Methods in Financial Engineering, Springer, New York, (2003).

[14] M. J. GoldBerg AND S. Kim, Applications of some formulas for finite Markov chains, Applied and Computational harmonic Analysis, 30 (2011), 37-46.

[15] J. Guo, Y. Wang, K. S. Tang, S. Chan, E. W. M. Wong, P. Taylor and M. Zukerman, Evolutionary optimization of file assignment for a large-scale video-on-demand system, IEEE Transactions on Knowledge and Data Engineering, 20 (2008), 836-850. 
[16] J. Guo, E. W. M. Wong, S. Chan, P. Taylor, M. Zukerman and K. S. Tang, Combination load balancing for video-on-demand systems, IEEE Transactions on Circuits and Systems for Video Technology, 18 (2008), 937-948.

[17] M. J. Hastings, Monte Carlo sampling methods using Markov chains and their applications, Biometrika, 57 (1970), 97-109.

[18] A. Новоцтн, A Markov chain Monte Carlo expectation maximization algorithm for statistical analysis of DNA sequence evolution with neighbour-dependent substitution rates, Journal of Computational and Graphical Statistics, 17 (2008), 138-164.

[19] A. Новоlth And E. A. Stone, Efficient simulation from finite-state, continuous-time Markov chains with incomplete observations, Ann. Appl. Statist., 3 (2009), 1204-1231.

[20] A. J. Kleywegte, A. Shapiro and T. Homem-De-Mello, Society for Industrial and Applied Mathematics, In: Technical report, Schuijbroek, 12 (2) (2001), 479-502.

[21] V. G. KULKARnI, Introduction to Modeling and Analysis of Stochastic systems, Springer, New York, (2011).

[22] H. NiederReIter (Eds), Random Number Generation and Quasi-Monte Carlo Methods, SIAM, Philadelphia, (1992).

[23] J. Schuijbroek, R. Hampshire ANd W. J. VAn Hoeve, Inventory rebalancing and vehicle routing in bike sharing systems, In: Technical report, Schuijbroek, http://repository.cmu.edu/ tepper/1491/, (Accessed September 2014), (2013). 